\title{
Enzymatic detoxification of the fumonisin mycotoxins during dry milling of maize
}

\author{
Johanna F. Alberts ${ }^{\mathrm{a}, *}$, Ibtisaam Davids ${ }^{\mathrm{b}}$, Wulf-Dieter Moll ${ }^{\mathrm{c}}$, Gerd Schatzmayr ${ }^{\mathrm{c}}$, \\ Hester-Mari Burger $^{d}$, Gordon S. Shephard ${ }^{e}$, Wentzel C.A. Gelderblom ${ }^{f}$ \\ ${ }^{a}$ Department of Food Science and Technology, Cape Peninsula University of Technology, Bellville, 7535, South Africa \\ ${ }^{\mathrm{b}}$ Department of Biomedical Science, University of the Western Cape, Bellville, 7535, South Africa \\ ${ }^{\mathrm{c}}$ BIOMIN Research Center, BIOMIN, Technopark 1, 3430, Tulln, Austria \\ ${ }^{\mathrm{d}}$ Unit of Research Integrity, Research Directorate, Cape Peninsula University of Technology, Bellville, 7535, South Africa \\ ${ }^{\mathrm{e}}$ Institute of Biomedical and Microbial Biotechnology, Cape Peninsula University of Technology, Bellville, 7535, South Africa \\ ${ }^{\mathrm{f}}$ Department of Biochemistry, Stellenbosch University, Private Bag X1, Matieland, 7602, South Africa
}

\section{A R T I C L E I N F O}

\section{Keywords:}

Fumonisin

Dry milling

Maize

FumD

Detoxification

Hydrolysis rate

Exposure assessment

\begin{abstract}
A B S T R A C T
Fumonisin esterase FumD (EC 3.1.1.87), FUMzyme ${ }^{\circledR}$ (BIOMIN, Austria), effectively detoxifies fumonisin B mycotoxins (FB) by hydrolysis and removal of the tricarballylic acid groups. The current study evaluated FumD detoxification of total $\mathrm{FB}\left(\mathrm{FB}_{\mathrm{T}}\right)$ in commercial maize utilising an experimental dry milling plant by introducing the enzyme during the kernel conditioning stage. Total $\mathrm{FB}$ and the hydrolysed product of $\mathrm{FB}_{1}, \mathrm{HFB}_{1}$, in maize and milling products were determined by LC-MS/MS. During maize conditioning of $4 \mathrm{~h} 10$ min substantial $\mathrm{FB}_{1}$ hydrolysis was achieved between 1 and $4 \mathrm{U}$ FumD/100 g maize. Complete conversion into HFB $_{1}$ was delayed and only achieved at the highest enzyme concentration (32 U/100 g maize) reaching a 1:1 M conversion ratio. Dry milling of maize containing $3.29 \pm 0.20 \mu$ mole $\mathrm{FB}_{\mathrm{T}} / \mathrm{kg}(2354 \pm 140 \mu \mathrm{g} / \mathrm{kg})$ in the absence of FumD, resulted in a 2.5 -fold increase in the $\mathrm{FB}_{\mathrm{T}}$ concentration in total hominy feed $(8.34 \pm 0.22 \mu \mathrm{mol} / \mathrm{kg})(5979 \pm 158 \mu \mathrm{g} / \mathrm{kg})$ compared to the levels that prevail in Super $(0.52 \pm 0.07 \mu \mathrm{mol} / \mathrm{kg})(347 \pm 48 \mu \mathrm{g} / \mathrm{kg})$ and Special $(1.70 \pm 0.01$ $\mu \mathrm{mol} / \mathrm{kg})(1213 \pm 8 \mu \mathrm{g} / \mathrm{kg})$ maize meal, and Semolina $(1.07 \pm 0.14 \mu \mathrm{mol} / \mathrm{kg})(765 \pm 100 \mu \mathrm{g} / \mathrm{kg}) \mathrm{milling}$ products. Introduction of FumD $(40 \mathrm{U} / \mathrm{kg}$ ) mainly impacted the total hominy feed product (germ + hominy milling fractions), constituting up to $30 \%$ of the reconstituted whole maize. A $99 \%$ reduction in $\mathrm{FB}_{\mathrm{T}}$ was obtained in total hominy feed, $48 \%$ in Semolina, $7 \%$ in Special maize meal, whereas no reduction was recorded in Super maize meal. $\mathrm{FB}_{1}$ reduction rates depend on the contamination level, kernel moisture and the diffusion rate from inner kernel layers to the kernel surface/aqueous interface. Risk modelling in children and adults indicated that FumD-treated whole maize and the resultant Semolina milling product intended for human consumption reduces the risk of exposure to $\mathrm{FB}_{\mathrm{T}}$. However, no reduction in the exposure risk was observed when considering the Super and Special maize meal milling products. FB reduction in total hominy feed could open up new applications, such as its dietary incorporation as a source of fibre, minerals and bioactive plant constituents in maize-based food. In addition, the animal feed industry and subsistence maize farming communities using rudimentary milling processes, could also benefit.
\end{abstract}

\section{Introduction}

Maize is an important staple food commodity in southern Africa and frequently contaminated with unacceptable levels of the fumonisin B (FB) mycotoxins, specifically in certain subsistence farming communities where regulations are either lacking or not enforced (Alberts,
Rheeder, et al., 2019; Alberts, Schatzmayr, et al., 2019). Although commercial maize is contaminated with lower levels, high consumption levels could be a risk factor for disease development in impoverished communities (Burger et al., 2010; Tshalibe et al., 2020).

Milling of maize is a physical process regarded as the first step in the production of maize-based products by removing the outer structures,

\footnotetext{
* Corresponding author.

E-mail addresses: albertsh@cput.ac.za (J.F. Alberts), 3343572@myuwc.ac.za (I. Davids), dieter.moll@biomin.net (W.-D. Moll), gerd.schatzmayr@biomin.net (G. Schatzmayr), burgerh@cput.ac.za (H.-M. Burger), gshephard@mweb.co.za (G.S. Shephard), gelderblom@sun.ac.za (W.C.A. Gelderblom).
} 
the pericarp (bran or hull), germ and tip cap to expose the endosperm, which is utilised to produce various milling products such as the grits, germ, meal and flour (Burger et al., 2013). In South Africa, dry milling comprises three main steps, i.e. conditioning, degerming to remove the outer kernel structures, and milling, to produce various milling products such as Special maize meal, Super maize meal, Semolina and total hominy feed (large pieces of pericarp with some endosperm attached and clean medium sized pieces of pericarp as well as the remnants of the tip cap). The milling products mostly utilised as human foodstuffs are the flaking grits and flour (Special maize meal), whereas the bran and germ milling products (total hominy feed) are mainly used for animal feed (Sharma et al., 2008) and as a source of fibre in human foods (Ai \& Jane, 2016). Maize bran produced during dry milling is preferred by the food industry above other sources of bran, being easier to process and incorporate into extruded food products and bakery goods.

Due to the complexity of the milling process mycotoxins are unevenly distributed in the various milled products (Burger et al., 2013; Vanara et al., 2018). Fumonisin mycotoxins are known to be mainly concentrated in the surface layers of the maize kernel and the resultant milling products such as the germ, pericarp and tip cap product (total hominy feed) contain high levels due to fungal colonisation of mainly the outer layers of the kernel with contamination progressing into the inner layer as a function of time (Brera et al., 2004; Rosenstrater \& Evers, 2018). During dry milling, the degerming process concentrates the fumonisins mainly in the hominy fraction (Burger et al., 2013). Therefore, the efficiency of degerming also affects the yield and composition of the grits whilst impacting on the levels of fumonisins in milling products. During subsequent milling of degermed maize, total fumonisins were more associated with Special maize meal known to contain less endosperm and some of the pericarp, germ and tip cap. The lowest percentage total fumonisin distribution was located in Super maize meal consisting of the coarse granulated endosperm. The level of mycotoxin contamination in whole maize and the distribution thereof between milling products is a food safety challenge. Studies investigating the effect of commercial milling on $\mathrm{FB}_{1}$ confirmed a reduction in contamination levels in the resultant dry milling products intended for human consumption (Burger et al., 2013). The reduction in total FB $\left(\mathrm{FB}_{\mathrm{T}}\right)$ during commercial dry milling in products intended for human consumption (Special and Super maize meal) therefore also reduced the risk of exposure among maize consumers (Burger et al., 2013, 2014). However, in a maize producing country such as South Africa, the pronounced maize consumption patterns may still increase risk of exposure (Burger et al., 2014). The balance between the production of commercial maize and the regulation and control of mycotoxins within South Africa, therefore, remains a challenge (Burger et al., 2014; Shephard et al., 2019).

The lack of effective and environmentally safe chemical control methods for FB in maize has led to investigations into biologically safe alternatives to prevent these contaminants from entering the food chain (Alberts et al., 2016; Alberts, Schatzmayr, et al., 2019). Enzymatic detoxification of FB has become a promising approach, with a focus on targeted modification of the chemical structures of the fumonisins by enzymatic cleavage or hydrolysis of chemical bonds/groups that play a key role during cytotoxicity (Alberts, Schatzmayr, et al., 2019; Grenier et al., 2017; Heinl et al., 2010). The discovery of a fumonisin esterase FumD (EC 3.1.1.87), FUMzyme ${ }^{\circledR}$ (BIOMIN, Austria) capable of effectively detoxifying the fumonisin mycotoxins by hydrolysis and formation of hydrolysed $\mathrm{FB}_{1}\left(\mathrm{HFB}_{1}\right)$, resulted in the development of a FumD $\mathrm{FB}$ reduction method in a maize kernel enzyme incubation mixture (Alberts, Schatzmayr, et al., 2019). FumD detoxification resulted in a significant reduction $(\geq 80 \%)$ of $\mathrm{FB}$ in contaminated maize kernels with a complete hydrolysis of $\mathrm{FB}_{1}$ to $\mathrm{HFB}_{1}$ as indicated by an approximate 1:1 $\mathrm{M}$ ratio. It has been suggested, based on the outcomes of the FumD FB reduction method, that it could find broader application, i.e. commercial maize-based milling practices.

The present study evaluated fumonisin esterase FumD for detoxification of $\mathrm{FB}_{1}$ in a commercial dry milling plant under experimental conditions. The enzyme was introduced during the initial conditioning step, prior to the degerming step of the milling process. The study evaluated the efficacy of FumD detoxification of FB as well as the distribution of $\mathrm{FB}_{1}$ and $\mathrm{HFB}_{1}$ in milling products intended for human food and animal feed production. In addition, the impact of FumD reduction in maize milling products on mycotoxin risk assessment in South African children and adults was assessed utilising maize intakes and body weight data form various national dietary surveys.

\section{Materials and methods}

\subsection{Chemicals}

Methanol, acetonitrile, formic acid (HPLC grade) and Whatman filter paper were obtained from Merck (Darmstadt, Germany). Water for all experiments was successively purified by reverse osmosis followed by Milli-Q water purification (Millipore, Massachusetts, USA).

\subsection{Experimental maize sample}

Commercial whole white maize $(120 \mathrm{~kg})$ was obtained from a prominent South African grain-based manufacturing company. The bulk was thoroughly mixed and divided into six subsamples. Four incremental samples (250-300 g each) were taken from each subsample, pooled and thoroughly mixed. This sample was further divided into two additional subsamples where after one $(3.3 \mathrm{~kg})$ was randomly selected for FB analyses. Samples were ground in a laboratory mill (Falling Number AB, Stockholm, Sweden) and kept in airtight containers at $-20^{\circ} \mathrm{C}$ until analysed. The remaining pooled samples were kept at $20^{\circ} \mathrm{C}$ until used in the milling experiments. Control maize containing no FB was obtained from the Southern African Grain Laboratory (SAGL) (Pretoria, South Africa) and used for the preparation of a maize extract used for matrix-matched LC-MS/MS calibration curves for FB analyses.

\subsection{FumD enzyme preparation}

A fumonisin esterase, designated FumD (EC 3.1.1.87; FUMzyme ${ }^{\circledR}$ ), was obtained from BIOMIN (Tulln, Austria) with a specific activity of 10 $000 \mathrm{U} / \mathrm{g}$. One unit is the enzymatic activity defined to release $1 \mu \mathrm{mol}$ tricarballylic acid per minute from $100 \mu \mathrm{M} \mathrm{FB}_{1}$ in $20 \mathrm{mM}$ Tris-HCl buffer $\mathrm{pH} 8.0$ containing $0.1 \mathrm{mg} / \mathrm{ml}$ bovine serum albumin at $30^{\circ} \mathrm{C}$. A stock FumD solution $(20 \mathrm{U} / \mathrm{ml})$ was prepared in distilled water.

\subsection{Preliminary experiment for selection of optimal FumD activity for $F B_{1}$ hydrolysis during the conditioning stage}

Whole maize was screened and cleaned from non-kernel impurities by hand and the percentage moisture content determined with a Grain Analysis Computer (Dickey-John GAC 2100, USA) (five replicates). Maize $(100 \mathrm{~g})$ was weighed out in containers $(300 \mathrm{ml})$ with tight fitting lids. Conditioning was conducted by adding water to adapt the moisture content of maize in order to create differential swelling resulting from the higher absorbing moisture of germ and pericarp. The conditioning step leads to loosening of the germ and pericarp from the endosperm to aid their removal (Eckhoff, 2004; Vanara et al., 2018). It is important to note that each commercial mill is likely to have its own particular conditioning procedure. Conditioning of samples was performed in two stages, i.e. (i) softening and (ii) loosening of the pericarp in order to facilitate the degerming process (Burger et al., 2013). The following formula was used to determine the volume of water to be added to obtain a moisture content of $14.5 \%$ in the maize samples.

Mass x (Target moisture \% - Actual moisture \%) / (100-Target moisture \%)

FumD solutions, 2, 4, 8, 16 and $32 \mathrm{U}$ per $100 \mathrm{~g}$ maize, were prepared 
in distilled water and added ( $\pm 2 \mathrm{ml}$ ) during the first conditioning stage to facilitate a moisture content of $14.5 \%$. Five replicates per treatment and reference water controls were included. The containers were transferred to a sealed bucket and rolled horizontally on an in-house rolling device at ambient temperature for $1 \mathrm{~h}$ and left standing for an additional $3 \mathrm{~h}$. For the second conditioning stage, distilled water $( \pm 2 \mathrm{ml})$ was added to each sample to $16.5 \%$ moisture content and rolled horizontally for $10 \mathrm{~min}$. The maize was ground in a laboratory mill (Falling Number $\mathrm{AB}$, Stockholm, Sweden) to a fine meal and kept in airtight containers at $-20^{\circ} \mathrm{C}$ until $\mathrm{FB}$ and $\mathrm{HFB}_{1}$ analyses.

\subsection{FB degradation during dry milling of maize}

Whole maize was weighed out $(3 \times 1.5 \mathrm{~kg})$ in buckets $(5 \mathrm{~L})$ with tight fitting lids. FumD solution was added to a final concentration of $40 \mathrm{U} / \mathrm{kg}$ based on the optimal $\mathrm{FB}_{1}$ hydrolysis obtained during the preliminary experiment and conditioning conducted as described above. Degerming was performed as described by Burger et al. (2013) producing two products, i.e. (i) germ (a mixture of the pericarp and tip cap) and (ii) degermed maize (endosperm and remnants of the germ). The resultant germ and degermed maize were weighed and the germ stored at $-20{ }^{\circ} \mathrm{C}$ in sealed containers. The degermed maize was further processed in an experimental dry milling plant (Buhler MIJJ-202 laboratory mill, Buhler, Switzerland), producing nine milling fractions from each sample (B1-3; S1-3; H1-2 and Semolina). The fractions were combined into four main milling products, i.e. Special and Super maize meal; Semolina and total hominy feed (the latter containing kernel surface layers, i.e. pericarp and tip cap) as described previously (Burger et al., 2013). Two independent experiments were performed and reference water control samples were included.

\section{6. $\mathrm{FB}$ and $\mathrm{HFB}_{1}$ analyses}

$\mathrm{FB}_{1}, \mathrm{FB}_{2}, \mathrm{FB}_{3}$ and $\mathrm{HFB}_{1}$ concentrations were determined in the original maize sample (five replicates), the water control and FumD treated samples obtained from conditioning, as well as in milling products and reconstructed whole maize and degermed maize (three to five replicates). Analytical standards of $\mathrm{FB}_{1}, \mathrm{FB}_{2}, \mathrm{FB}_{3}$ and $\mathrm{HFB}_{1}$ (purity $>97 \%$ ) were prepared at the Cape Peninsula University of Technology, South Africa, according to the methods of Cawood et al. (1991) and Gelderblom et al. (1993). Stock solutions of the individual purified fumonisin standards were prepared $\left[1 \mathrm{mg} / \mathrm{ml}\right.$ in acetonitrile- $\left.\mathrm{H}_{2} \mathrm{O}(1: 1)\right]$ and aliquots used to prepare an evaporated working solution containing the fumonisin standards at individual concentrations of $5 \mu \mathrm{g} / \mathrm{ml}$ (Alberts, Schatzmayr, et al., 2019). For compiling matrix-matched calibration curves, five working standard dilutions were prepared with blank maize matrix extract as solvent, as described below.

Validated extraction and LC-MS/MS quantification methods were used (Tables 1 and 2) (Alberts, Schatzmayr, et al., 2019). Briefly, $100 \mathrm{ml}$ of extraction solvent [methanol: acetonitrile: water (25:25:50; v/v/v)] was added to ground maize ( $10 \mathrm{~g}$ ) and placed on a shaker $(80 \mathrm{rpm})$ for $20 \mathrm{~min}$. The extracts were subsequently centrifuged $(4000 \times \mathrm{g})$ in a refrigerated Sorvall RC-3B centrifuge (DuPont, Norwalk, Connecticut, USA) at $4{ }^{\circ} \mathrm{C}$ for $10 \mathrm{~min}$. The supernatant was diluted (1:1) with methanol:water (25:75), filtered (Whatman No 4 filter paper) and filtrates

Table 1

LC-MS/MS conditions for quantification of fumonisins and $\mathrm{HFB}_{1}$ by positive ESI at capillary voltage $3.5 \mathrm{kV}$.Table 2

\begin{tabular}{lllll}
\hline Analyte & $\begin{array}{l}\text { Cone } \\
\text { voltage (V) }\end{array}$ & Precursor & $\begin{array}{l}\text { Quantifier } \\
\text { [Collision energy } \\
(\mathrm{V})]\end{array}$ & $\begin{array}{l}\text { Qualifier } \\
\text { [Collision energy } \\
(\mathrm{V})]\end{array}$ \\
\hline $\mathrm{FB}_{1}$ & 50 & 722.3 & $334.3[40]$ & $352.3[38]$ \\
$\mathrm{FB}_{2}$ and & 50 & 706.3 & $318.3[40]$ & $336.3[40]$ \\
$\mathrm{FB}_{3}$ & & 406.6 & $334.3[25]$ & $352.4[20]$ \\
$\mathrm{HFB}_{1}$ & 25 & & & \\
\hline
\end{tabular}

Table 2

Validation of the analytical method for fumonisin analyses in maize.

\begin{tabular}{lllll}
\hline Analyte & $\begin{array}{l}\mathrm{LOQ} \\
(\mu \mathrm{g} / \mathrm{kg})\end{array}$ & $\begin{array}{l}\text { Spike level } \\
(\mu \mathrm{g} / \mathrm{kg})\end{array}$ & $\begin{array}{l}\text { Recovery } \\
(\%)\end{array}$ & $\begin{array}{l}\mathrm{RSDr} \\
(\%)\end{array}$ \\
\hline $\mathrm{FB}_{1}$ & 3.5 & 1060 & 84 & 2 \\
$\mathrm{FB}_{2}$ & 2.8 & 925 & 66 & 4 \\
$\mathrm{FB}_{3}$ & 2.8 & 520 & 79 & 1 \\
$\mathrm{HFB}_{1}$ & 2.8 & 800 & 80 & 2 \\
\hline
\end{tabular}

LOQ, Lower limit of quantification; RSDr, Relative standard deviation for repeatability.

analysed by direct injection into the LC-MS/MS. FAPAS (London, England) quality control reference maize samples (Cat no T22123QC), containing the mycotoxins in known concentration ranges, were included. Matrix-matched standard solutions for calibration curves were prepared utilising an extract prepared from control maize.

Quantification of $\mathrm{FB}$ and $\mathrm{HFB}_{1}$ in the original maize sample and milling products was performed by the Mass Spectrometry Unit of the Central Analytical Facility of Stellenbosch University, South Africa. FB and $\mathrm{HFB}_{1}$ levels in the original maize sample were confirmed by SAGL. The mycotoxins were separated on a reversed-phase BEH C18 column $(2.1 \times 100 \mathrm{~mm}$; particle size $1.7 \mu \mathrm{m})$ (Waters, Milford, Massachusetts, USA) and analysed with positive electrospray ionisation (ESI) in the multiple reaction monitoring (MRM) mode in a Waters Acquity Ultra high performance liquid chromatograph (UPLC) coupled to a tandem quadrupole mass spectrometer (Waters Xevo TQ MS, Milford, Massachusetts, USA). Eluent A was water and eluent B was methanol, both containing $0.1 \%$ formic acid. The chromatographic method held the initial mobile phase composition (15\% B) constant for 2 min, followed by a linear gradient to $100 \% \mathrm{~B}$ within $3 \mathrm{~min}$. This final condition was held for $3 \mathrm{~min}$, followed by $8 \mathrm{~min}$ of column re-equilibration at $15 \% \mathrm{~B}$. The flow rate of the mobile phase was $0.35 \mathrm{ml} / \mathrm{min}$. For each compound, one precursor and two product ions were monitored, one product ion for quantification and one for confirmation. A calibration curve consisting of five matrix-matched standards for each mycotoxin was used for quantification.

\subsection{Fumonisin risk modelling and assessment}

\subsubsection{Body weights}

Three distinct age groups, children $1-5$ and $6-9$ years old and adults aged 17 years and above were chosen due to the availability of national maize consumption and body weights for these specific age groups. Average body weight used for the $1-5$ year old children was calculated by using the mean body weight of children aged 12-23 months (11 kg) and that of children aged $2-5$ years $(16 \mathrm{~kg})$ obtained from the South African National Health and Nutrition Examination Survey (SANHANES-1) (Shisana et al., 2014). The body weights of children 6-9 years of age were obtained from the same survey and was reported as $24.4 \mathrm{~kg}$. The average weight of adult South Africans ( $\geq 17$ years) were obtained from a national maize consumer survey conducted among adults and was taken as $74.0 \mathrm{~kg}$ (Burger et al., 2014).

\subsubsection{Maize intakes}

Average total cooked maize intakes in grams per day ( $g$ /day) for the 1-5 and 6-9 year old groups, were obtained from the secondary data analysis of various South African dietary surveys and were reported as 364.3 and $392.9 \mathrm{~g} /$ day, respectively (Steyn et al., 2003). The average dry maize intake for South African adults ( $157.0 \mathrm{~g} /$ day) was calculated using data obtained from a national maize consumption survey among 2809 adults (Burger et al., 2014).

\subsubsection{Risk modelling and assessment}

In order to conduct mycotoxin risk assessment by calculating a probable daily intake (PDI in $\mu \mathrm{g} / \mathrm{kg}$ body weight (bw)/day), the 
consumption of the dry (raw) maize as opposed to cooked maize is of importance. To compensate for cooking ingredients, the traditional recipe for maize porridge was used arbitrarily to estimate dry intake and each average intake for the various groups were divided by a special factor. This factor was calculated specifically for the purposes of mycotoxin risk assessment using dietary intakes to calculate exposure (Lombard et al., 2014). Probable daily intakes were calculated using $\mathrm{FB}_{\mathrm{T}}$ levels $\left(\mathrm{FB}_{1}+\mathrm{FB}_{2}+\mathrm{FB}_{3}\right.$ in $\left.\mu \mathrm{g} / \mathrm{kg}\right)$ in various milling fractions treated with and without FumD, average body weights and dry maize intakes stratified by age. The PDI for FB for each age group was evaluated against the provisional maximum tolerable daily intake (PMTDI) set by the Joint Food and Agriculture Organization of the United Nations (FAO)/World Health Organization (WHO) Expert Committee on Food Additives (JECFA) for exposure in humans (WHO, 2001).

\subsection{Statistical analyses}

The NCSS software (2019) was used for statistical analysis. Data were subjected to natural $\log (\ln )$ transformation of all variables and analysed within a generalised linear model ANOVA. Multiple comparisons were analysed using the Tukey-Kramer's multiple comparison procedure. This method provides joint simultaneous confidence intervals for all pairwise differences between the means; and also provides the multiple comparison P-value. Generally, $\mathrm{P}<0.05$ was used as statistical significance. In addition, the size of the F-ratios was used to measure relative sizes of differences.

\section{Results}

\subsection{Preparation of milling products and reconstruction of whole maize and degermed maize}

Milling products were prepared by combining the relevant milling fractions, i.e. Special maize meal (fractions B1-B3), Super maize meal (fractions S1-S3), Semolina and total hominy feed (Germ and fractions $\mathrm{H} 1-\mathrm{H} 2$ ) (Table 3). The percentage of each milling product produced was recorded, ensuring that the correct ratios are used during reconstruction of whole and degermed maize samples. Reconstruction was conducted to provide a more accurate fumonisin concentration in the original and degermed maize samples (Burger et al., 2013).

\section{2. $F B$ and $H F B_{1}$ concentrations and percentage moisture content in maize}

$\mathrm{FB}$ and $\mathrm{HFB}_{1}$ concentrations $(\mu \mathrm{g} / \mathrm{kg})$ in the original maize sample (mean values \pm standard deviation): $\mathrm{FB}_{1}, 1614 \pm 130(2.24 \pm 0.18$ $\mu \mathrm{mol} / \mathrm{kg}) ; \mathrm{FB}_{2}, 359 \pm 22(0.51 \pm 0.03 \mu \mathrm{mol} / \mathrm{kg}) ; \mathrm{FB}_{3}, 137 \pm 13(0.19 \pm$ $0.02 \mu \mathrm{mol} / \mathrm{kg}) ; \mathrm{HFB}_{1}, 2 \pm 1(0.01 \pm 0.00 \mu \mathrm{mol} / \mathrm{kg})$. Mean moisture content (\%) of samples: $12.53 \pm 0.12$.

\subsection{Percentage recovery during degerming and dry milling}

The percentage loss of maize during experimental dry milling was determined as described by Burger et al. (2013). An average sample loss of $2.20 \pm 0.01 \%$ was recorded for the water control maize and $2.23 \pm$ $0.09 \%$ for the FumD treated maize.

\subsection{Optimal FumD activity and hydrolysis ratios during conditioning prior to degerming and dry milling}

\subsection{1. $F B_{1}$ hydrolysis and formation of $H F B_{1}$ in maize as a function of FumD activity}

FB concentration was significantly $(\mathrm{P}<0.0001)$ reduced as a function of an increased enzyme activity (Fig. 1). Treatment with $\geq 1 \mathrm{U} / 100$ $\mathrm{g}$ maize equated to a $\geq 96 \%$ reduction in $\mathrm{FB}_{\mathrm{T}}$ concentrations when compared to the water control. No significant $(\mathrm{P}>0.05)$ differences existed in FB reduction between FumD activities $\geq 2 \mathrm{U} / 100 \mathrm{~g}$ maize. The reduction in $\mathrm{FB}_{1}$ concentrations coincided with a significant $(\mathrm{P}<0.05)$ increase in $\mathrm{HFB}_{1}$ concentrations $>1 \mathrm{U} / 100 \mathrm{~g}$ maize with no significant difference between FumD levels above $2 \mathrm{U} / 100 \mathrm{~g}$ maize. The untreated maize only has trace amounts of $\mathrm{HFB}_{1}$.

\subsubsection{Comparative enzyme hydrolysis rates}

Maximum $\mathrm{FB}_{1}$ hydrolysis was already reached in the maize samples in the presence of $1 \mathrm{U} / 100 \mathrm{~g}$ maize despite the fact that maximum release of $\mathrm{HFB}_{1}$ yields a $\mathrm{FB}_{1}: \mathrm{HFB}_{1}$ ratio of $1: 1$ and was only achieved at the highest (32 $\mathrm{U} / 100 \mathrm{~g}$ maize) FumD activity (Table 4). The calculated specific $\mathrm{FB}_{1}$ conversion rate decreased as a function of enzyme concentration, because of substrate depletion. However, the $\mathrm{HFB}_{1}$ formation rate remained constant and did not further decrease significantly ( $P$ $>0.05$ ) beyond $8 \mathrm{U} / 100 \mathrm{~g}$ maize, suggesting a delayed and/or

Table 3

Preparation of milling products and percentages (\%) of milling products used to reconstruct whole maize and degermed maize.

\begin{tabular}{|c|c|c|c|c|c|c|}
\hline \multirow[t]{2}{*}{ Maize } & \multirow{2}{*}{$\begin{array}{c}\text { Special } \\
\text { maize meal } \\
(B 1-B 3) \\
(\%)\end{array}$} & \multirow{2}{*}{$\begin{array}{c}\text { Super } \\
\text { maize meal } \\
(\text { S1-S3) } \\
(\%)\end{array}$} & \multirow[t]{2}{*}{$\begin{array}{c}\text { Semolina } \\
(\%)\end{array}$} & \multicolumn{3}{|c|}{${ }^{*}$ Total hominy feed } \\
\hline & & & & $\begin{array}{c}\text { Germ } \\
(\%)\end{array}$ & $\begin{array}{c}\text { Milling } \\
\text { hominy } \\
\text { feed } \\
\text { H1 } \\
(\%)\end{array}$ & $\begin{array}{c}\text { Milling } \\
\text { hominy } \\
\text { feed } \\
\mathrm{H} 2 \\
(\%)\end{array}$ \\
\hline \multicolumn{7}{|c|}{ Reconstructed whole maize } \\
\hline $\begin{array}{l}\text { Water } \\
\text { control }\end{array}$ & 11.2 & 44.8 & 15.3 & 23.7 & 2.8 & 2.2 \\
\hline FumD & 11.3 & 43.2 & 16.4 & 22.8 & 3.2 & 3.1 \\
\hline \multicolumn{7}{|c|}{ Reconstructed degermed maize } \\
\hline $\begin{array}{l}\text { Water } \\
\text { control }\end{array}$ & 14.7 & 58.6 & 20.0 & - & 3.7 & 2.9 \\
\hline FumD & 14.6 & 56.0 & 21.2 & - & 4.2 & 4.0 \\
\hline
\end{tabular}

*Total hominy feed: germ + milling hominy feed fractions $(\mathrm{H} 1$ and $\mathrm{H} 2)$. 


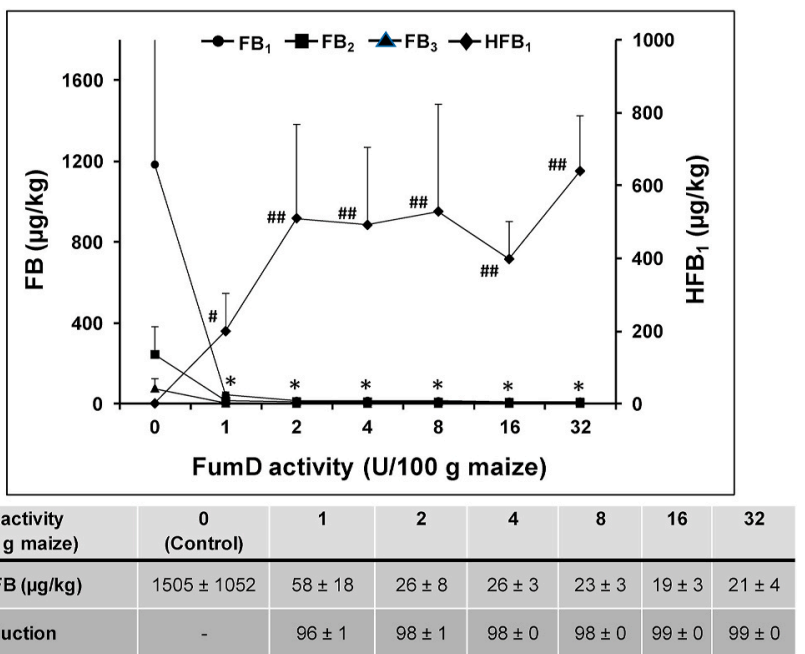

Fig. 1. Fumonisin $\mathrm{B}\left(\mathrm{FB}_{1}, \mathrm{FB}_{2}\right.$ and $\left.\mathrm{FB}_{3}\right)$ and hydrolysed fumonisin $\mathrm{B}_{1}\left(\mathrm{HFB}_{1}\right)$ concentrations $(\mu \mathrm{g} / \mathrm{kg})$ as a function of FumD activity $(0,1,2,4,8,16$, and 32 $\mathrm{U} / 100 \mathrm{~g}$ maize) after $4 \mathrm{~h} 10 \mathrm{~min}$ conditioning prior to degerming. Values represent means of five replications of experiments and error bars indicate standard deviations. The statistical analyses are based on natural $\log (\ln )$ transformations. The $\mu \mathrm{g} / \mathrm{kg}$ axes were scaled in the same proportion as the molar masses of $\mathrm{FB}_{1}$ and $\mathrm{HFB}_{1}$. The ${ }^{*}\left(\mathrm{FB}_{1}\right),\left(\mathrm{FB}_{2}\right),\left(\mathrm{FB}_{3}\right)$ and $\#\left(\mathrm{HFB}_{1}\right)$ indicate significant $(\mathrm{p}<0.0001)$ differences of means (all enzyme activities) from the water control (0 U/L) treatments. Table insert: Percentage (\%) reduction of the total FB as a function of FumD activity after $4 \mathrm{~h} 10 \mathrm{~min}$.

incomplete hydrolysis of $\mathrm{FB}_{1}$ into partially hydrolysed forms at lower enzyme activities, which is also reflected by the high $\mathrm{FB}_{1}: \mathrm{HFB}_{1}$ ratio.

\subsection{Distribution pattern of $F B_{T}, F B_{1}$ and $H F B_{1}$ in milling products}

The degerming step resulted in an almost $70 \%$ reduction in $\mathrm{FB}_{\mathrm{T}}$ with the remainder associated with the pericarp and germ (Fig. 2A). When compared to reconstructed whole maize, the bulk of $\mathrm{FB}_{\mathrm{T}}(72 \%)$ was associated with total hominy feed following dry milling in the absence of FumD (Fig. 2B). $\mathrm{FB}_{\mathrm{T}}$ was the lowest in the Super maize meal (5\%) followed by Semolina (9\%) and Special maize meal (15\%). Milling in the presence of FumD resulted in an almost complete loss (99\%) of the $\mathrm{FB}_{\mathrm{T}}$ in total hominy feed contributing only $3 \%$ of the $\mathrm{FB}_{\mathrm{T}}$ compared to the $72 \%$ in the untreated FumD maize (Fig. 2; Table insert). The Special maize meal contained the bulk $\mathrm{FB}_{\mathrm{T}}$ making up $55 \%$ with the Super maize meal and Semolina products containing in the order of $20 \%$.

The hydrolysis of $\mathrm{FB}_{1}$ into $\mathrm{HFB}_{1}$ during dry milling followed a similar pattern with more than $80 \%$ and almost $100 \%$ converted in the reconstructed whole maize and total hominy feed, respectively (Table 5). Very little hydrolysis was noticed in Super maize meal, while 7 and 50\% were converted in Special maize meal and Semolina, respectively. The HFB 1 formation followed a similar pattern with the highest level recorded in the total hominy feed followed by Semolina. However, no significant difference $(\mathrm{P}>0.05)$ was noticed between the $\mathrm{FB}_{1}: \mathrm{HFB}_{1}$ molar ratios recorded following the conditioning and milling procedure approaching 1:1 ratio, although it was markedly higher in Semolina. This again indicated the presence of partially hydrolysed $\mathrm{FB}_{1}$ in all the milling products.

\subsection{FB risk modelling and exposure assessment}

Maize milling products relevant to human consumption include the Special and Super maize meal and to a lesser extend Semolina and total hominy feed (Burger et al., 2013). The reduction in $\mathrm{FB}_{\mathrm{T}}$ levels by FumD in certain milling products is reflected in a lower PDI across all age groups (Table 6). For the 1-5 age group, the PDIs were below the PMTDI of $2 \mu \mathrm{g} / \mathrm{kg}$ bw/day for the FumD treated products except for the Special maize meal which contain relatively high $\mathrm{FB}_{\mathrm{T}}$ levels. A similar pattern was observed for the $6-9$ and $\geq 17$ year old groups, where PDIs above 2 $\mu \mathrm{g} / \mathrm{kg}$ bw/day, respectively were noted for Special maize meal even after treatment with FumD. Although not commonly consumed by humans, the reduction of FB levels by FumD in the total hominy feed resulted in a PDI far less than the untreated product and well below the PMTDI.

\section{Discussion}

Fumonisin esterase FumD effectively catalyses the degradation of FB into hydrolysed FB products, which have been shown to correlate with the reduction of toxicity in pigs and poultry (Grenier et al, 2013, 2017; Masching et al., 2016). This implies that FumD could find commercial application in the animal feed industry to effectively reduce FB exposure with beneficial economic implications. Very few studies have been conducted to utilise FumD to directly benefit humans to the extent that it could be used to reduce FB in food. One such approach has recently been reported whereby a FumD FB reduction method eradicated the mycotoxins in "low" and "high" FB contaminated home-grown maize (Alberts, Schatzmayr, et al., 2019). The method is envisaged to form part of community based approaches suggested to find application in subsistence farming communities utilising home-grown maize as main dietary staple and known to be exposed above the maximum tolerable daily intake levels of $2 \mu \mathrm{g} / \mathrm{kg}$ bw/day set by JECFA (Alberts et al., 2017; Burger et al., 2014; Shephard et al., 2019; Tshalibe et al., 2020).

At present it is not known whether the FumD FB reduction method could be also introduced during commercial milling practices of maize to facilitate FB degradation and reduce the levels in the products intended for human and animal food and feed. Differences in milling practices, kernel characteristics and the large quantities of maize utilised complicates the accurate assessment of distribution patterns of

Table 4

Rates of enzymatic hydrolysis for different FumD activities during $4 \mathrm{~h} 10 \mathrm{~min}$ conditioning prior to degerming.

\begin{tabular}{|c|c|c|c|c|c|}
\hline $\begin{array}{l}\text { FumD activity (U/ } \\
100 \mathrm{~g} \text { maize) }\end{array}$ & $\begin{array}{l}\mathrm{FB}_{1} \text { hydrolysed (nmole/ } \\
100 \mathrm{~g} \text { maize) }\end{array}$ & $\begin{array}{l}\mathrm{FB}_{1} \text { hydrolysis rate (nmole/ } \\
\mathrm{min} / \mathrm{mg} \text { enzyme) }\end{array}$ & $\begin{array}{l}\mathrm{HFB}_{1} \text { released (nmole/ } \\
100 \mathrm{~g} \text { maize) }\end{array}$ & $\begin{array}{l}\mathrm{HFB}_{1} \text { formation rate* (nmole/ } \\
\mathrm{min} / \mathrm{mg} \text { enzyme) }\end{array}$ & $\begin{array}{l}\mathrm{FB}_{1} \text { hydrolysed:HFB } \\
\text { formation molar ratio** }\end{array}$ \\
\hline 0 & - & - & $0.3 \pm 0.2 \mathrm{a}$ & - & - \\
\hline 1 & $158.4(2.1) \mathrm{a}$ & $6.3 \pm 0.1 \mathrm{a}$ & $48.7 \pm 25.6 \mathrm{a}$ & $2.0 \pm 1.0 \mathrm{a}$ & $4.2 \pm 2.3 \mathrm{a}$ \\
\hline 2 & $161.7(0.0) \mathrm{a}$ & $3.2 \pm 0.0 \mathrm{~b}$ & $103.1 \pm 47.0 \mathrm{~b}$ & $2.1 \pm 0.9 \mathrm{a}$ & $2.1 \pm 1.7 \mathrm{a}$ \\
\hline 4 & $162.2(0.4) \mathrm{a}$ & $1.6 \pm 0.0 \mathrm{c}$ & $120.3 \pm 52.3 b$ & $1.2 \pm 0.5 \mathrm{a}$ & $1.5 \pm 0.7 \mathrm{a}$ \\
\hline 8 & $162.4(0.2) \mathrm{a}$ & $0.8 \pm 0.0 \mathrm{~d}$ & $129.4 \pm 72.2 b$ & $0.7 \pm 0.4 \mathrm{ab}$ & $1.7 \pm 1.1 \mathrm{a}$ \\
\hline 16 & $162.8(0.3) \mathrm{a}$ & $0.4 \pm 0.0 \mathrm{e}$ & $97.1 \pm 25.3 b$ & $0.2 \pm 0.1 \mathrm{~b}$ & $1.8 \pm 0.5 \mathrm{a}$ \\
\hline 32 & $162.7(0.3) \mathrm{a}$ & $0.2 \pm 0.0 \mathrm{f}$ & $156.6 \pm 37.2 b$ & $0.2 \pm 0.1 b$ & $1.1 \pm 0.3 b$ \\
\hline
\end{tabular}

The statistical analyses are based on natural $\log (\ln )$ transformations. Values represent means \pm standard deviations of five replications of experiments. Statistical significant $(\mathrm{p}<0.05)$ differences in a column for FumD activities are indicated with different letters. ${ }^{*} \mathrm{HFB}_{1}$ levels were corrected accordingly in the presence of the enzyme. **Molar ratios of $\mathrm{FB}_{1}$ hydrolysed to $\mathrm{HFB}_{1}$ formed with a 1:1 ratio indicating a complete conversion. 
A

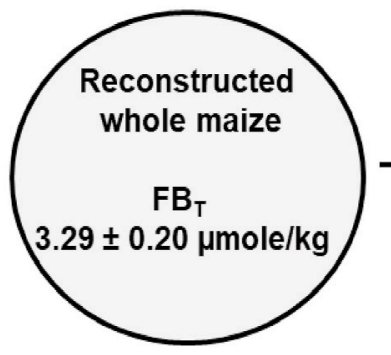

B

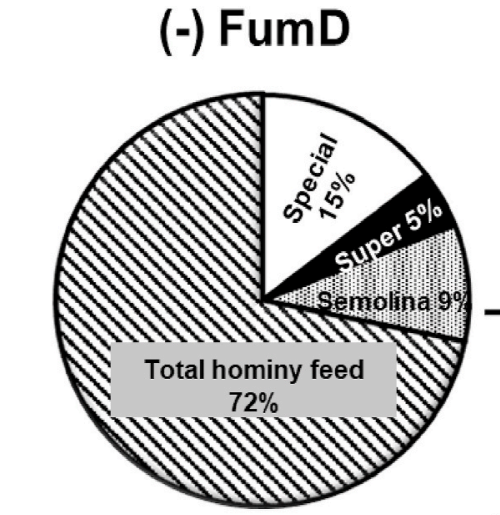

\section{$(-)$ FumD}

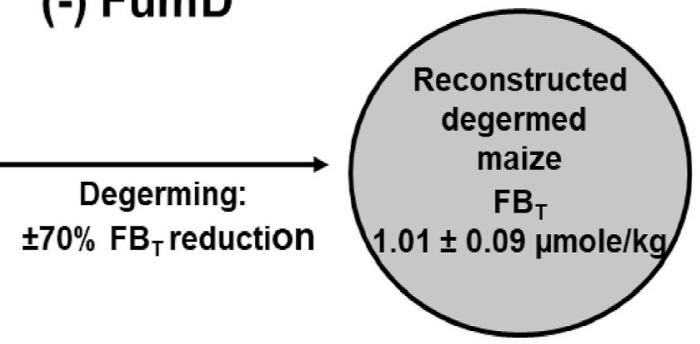

(+) FumD

Total hominy feed

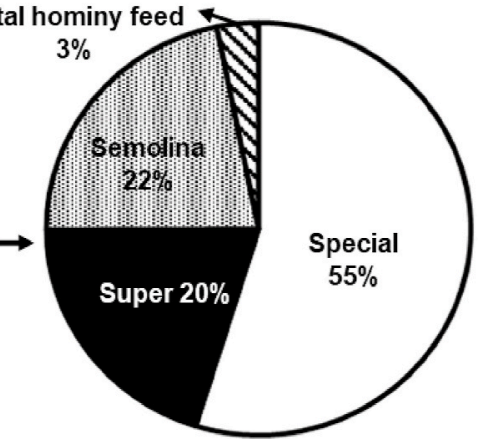

\begin{tabular}{c|c|c|c|}
\multirow{2}{*}{ Milling products } & \multicolumn{2}{|c|}{$\mathrm{FB}_{\mathrm{T}}(\mu \mathrm{mole} / \mathrm{kg})$} & $\begin{array}{c}\text { Mean } \% \\
\text { reduction/ } \\
\text { Increase }(-) /(+)\end{array}$ \\
\cline { 2 - 3 } & $(-)$ FumD & $(+)$ FumD & $(-) 7$ \\
Special maize meal & $1.70 \pm 0.01$ & $1.56 \pm 0.15$ & $(+) 10$ \\
Super maize meal & $0.52 \pm 0.07$ & $0.57 \pm 0.07$ & $(-) 48$ \\
Semolina & $1.07 \pm 0.14$ & $0.62 \pm 0.13$ & $(-) 99$ \\
\hline Total hominy feed & $8.34 \pm 0.22$ & $0.09 \pm 0.02$ & $(-) 21$ \\
Reconstructed degermed maize & $1.01 \pm 0.09$ & $0.62 \pm 0.05$ & $(-) 81$ \\
Reconstructed whole maize & $3.29 \pm 0.20$ & $0.79 \pm 0.01$ & $(-) 81$
\end{tabular}

Fig. 2. 2A, Reduction of total $\mathrm{FB}\left(\mathrm{FB}_{\mathrm{T}}\right)$ during degerming of whole maize in the absence of FumD; $2 \mathrm{~B}$, Distribution of $\mathrm{FB}_{\mathrm{T}}$ in dry milling products as a percentage of the total, in the absence and presence of FumD. Table insert; $\mathrm{FB}_{\mathrm{T}}$ levels ( $\mu$ mole $/ \mathrm{kg}$ maize) and percentage FumD-induced reduction/increase $(-/+)$ in the resultant milling fractions and reconstructed degermed and whole maize. Values represent means \pm standard deviations of triplicate analyses of two independent experiments.

mycotoxin into the different products (Burger et al., 2013). Experimental milling under controlled conditions, however, provides more accurate distribution patterns of the mycotoxins between the different milling products, which could provide a basis for application in commercial settings. A recent study indicated that conventional milling utilising an experimental dry milling plant, reduced mycotoxins FB, deoxynivalenol (DON) and zearalenone (ZEA) in milling products, whilst it was concentrated in total hominy feed generally intended for animal feed (Burger et al., 2013). A detailed risk analysis on the consumption of the milling products utilising a mycotoxin risk assessment model (MYCORAM) provided information on the potential adverse effects of FB, DON and ZEA based on exposure in populations above safe PMTDI levels in the Provinces of South Africa (Burger et al., 2014). The present study investigated the role of FumD on reduction and distribution of $\mathrm{FB}$ and $\mathrm{HFB}_{1}$ in different milling products as well as the impact on the levels of exposure of humans to FB in relation to risk assessment parameters and current FB mycotoxin regulations.

In the current study, effective hydrolysis of $\mathrm{FB}$ resulted in $\geq 96 \%$ reduction in maize by FumD ( $1 \mathrm{U} / 100 \mathrm{~g}$ maize) during the conditioning stage prior to degerming. A far lower enzyme activity (1-4 U/100 g

Table 5

FumD (40 U/kg maize) hydrolysis of $\mathrm{FB}_{1}$ into $\mathrm{HFB}_{1}$ during the full duration of the dry milling protocol as a function of $\mathrm{FB}_{1}: \mathrm{HFB}_{1}$ hydrolysis ratios in milling products.

\begin{tabular}{|c|c|c|c|c|c|}
\hline \multirow[t]{2}{*}{ Milling products } & \multicolumn{2}{|c|}{$\mathrm{FB}_{1}(\mu \mathrm{mole} / \mathrm{kg})$} & \multirow[t]{2}{*}{$\% \mathrm{FB}_{1}$ loss } & \multirow[t]{2}{*}{$\mathrm{HFB}_{1}$ formation* $(\mu$ mole $/ \mathrm{kg})$} & \multirow[t]{2}{*}{$\mathrm{FB}_{1}: \mathrm{HFB}_{1}$ molar ratio** } \\
\hline & $(-)$ FumD & $(+)$ FumD & & & \\
\hline Special maize meal & $0.90 \pm 0.03 a$ & $0.76 \pm 0.04 a$ & $14.86 \pm 0.99 \mathrm{a}$ & $0.10 \pm 0.02 \mathrm{a}$ & $1.4 \pm 0.34 a$ \\
\hline Super maize meal & $0.27 \pm 0.04 \mathrm{~b}$ & $0.29 \pm 0.05 b$ & $\mathrm{n} / \mathrm{a}$ & $0.03 \pm 0.00 \mathrm{~b}$ & $\mathrm{n} / \mathrm{a}$ \\
\hline Semolina & $0.68 \pm 0.12 c$ & $0.34 \pm 0.11 b$ & $50.59 \pm 15.56 b$ & $0.17 \pm 0.02 c$ & $2.00 \pm 0.44 \mathrm{~b}$ \\
\hline Reconstructed whole maize & $1.93 \pm 0.13 \mathrm{~d}$ & $0.34 \pm 0.07 b$ & $82.68 \pm 3.44 c$ & $1.22 \pm 0.10 \mathrm{~d}$ & $1.30 \pm 0.10 \mathrm{a}$ \\
\hline Reconstructed degermed maize & $0.55 \pm 0.02 c$ & $0.41 \pm 0.03 b$ & $26.17 \pm 5.82 \mathrm{~d}$ & $0.09 \pm 0.00 \mathrm{a}$ & $1.56 \pm 0.37 \mathrm{a}$ \\
\hline Total hominy feed & $5.66 \pm 0.19 \mathrm{e}$ & $0.06 \pm 0.02 c$ & $98.86 \pm 0.33 \mathrm{e}$ & $4.31 \pm 0.15 \mathrm{e}$ & $1.30 \pm 0.04 a$ \\
\hline
\end{tabular}

Values represent means \pm standard deviations of three replicates. The statistical analyses are based on natural $\log (\ln )$ transformations. Statistical significant ( $\mathrm{p}<0.05)$ differences in a column between the control and FumD treatments are indicated with different letters. ${ }^{*} \mathrm{HFB}_{1}$ levels were corrected accordingly in the presence of the enzyme. $\mathrm{n} / \mathrm{a}$, not applicable. **Molar ratios of $\mathrm{FB}_{1}$ hydrolysed to $\mathrm{HFB}_{1}$ formed. 
Table 6

Fumonisin B (FB) risk modelling among South African children and adults using different dry maize intakes and body weights available from national dietary surveys.

\begin{tabular}{|c|c|c|c|c|c|c|c|c|}
\hline Age groups (years) & & \multicolumn{3}{|c|}{ Children 1-5 } & \multicolumn{3}{|c|}{ Children 6-9 } & Adult $\geq 17$ \\
\hline Average weight (kg) & & \multicolumn{3}{|l|}{$13.5^{*}$} & \multicolumn{3}{|l|}{$24.4^{*}$} & $74.0 * *$ \\
\hline Average dry maize intake ( $\mathrm{g} /$ day) & & \multicolumn{3}{|l|}{$49.8^{\#}$} & \multicolumn{3}{|l|}{$53.7^{\#}$} & $157.0^{\# \#}$ \\
\hline Average dry maize intake (g/day/kg bw) & & \multicolumn{2}{|l|}{3.69} & & \multicolumn{2}{|l|}{2.20} & & 2.85 \\
\hline \multirow[t]{3}{*}{ Milling products relevant to human consumption } & \multicolumn{2}{|c|}{$\begin{array}{l}\text { Average } \mathrm{FB}_{\mathrm{T}} \\
(\mu \mathrm{g} / \mathrm{kg})^{\phi}\end{array}$} & \multicolumn{4}{|c|}{$\begin{array}{l}\text { PDI } \\
(\mu \mathrm{g} / \mathrm{kg} \text { bw/day) }\end{array}$} & & \\
\hline & $(-)$ & $(+)$ & $(-)$ & $(+)$ & $(-)$ & $(+)$ & $(-)$ & $(+)$ \\
\hline & FumD & FumD & FumD & FumD & FumD & FumD & FumD & FumD \\
\hline Reconstructed whole maize & 2354 & 445 & 8.7 & 1.6 & 5.2 & 1.0 & 5.0 & 0.9 \\
\hline Special maize meal & 1213 & 1127 & 4.5 & 4.1 & 2.7 & 2.5 & 2.6 & 2.4 \\
\hline Super maize meal & 374 & 414 & 1.4 & 1.5 & 0.8 & 0.9 & 0.8 & 0.9 \\
\hline Semolina & 765 & 450 & 2.8 & 1.7 & 1.7 & 1.0 & 1.6 & 1.0 \\
\hline Total hominy feed & 5979 & 65 & 22.0 & 0.2 & 13.2 & 0.1 & 12.7 & 0.1 \\
\hline
\end{tabular}

*Average weight of children aged 12-23 months (11 kg) and children aged 2-5 years (16 kg), as well as the weight (24.4 kg) of children 6-9 years (Shisana et al., 2014). **Average weight of adult South African maize consumers (74.0 kg) ( $\mathrm{n}=2809)$ (Burger et al., 2014). ${ }^{\#}$ Mean maize intakes for South African children aged 1-5 years (364.3 g/day) and 6-9 years (392.9 g/day) (Steyn et al., 2003) were used to calculate the respective dry weight intakes, using the recipe for soft maize meal porridge to correct for ingredients (Lombard et al., 2014). \#\# Mean dry maize intake of adult South African maize consumers (numerical mean of $157.0 \mathrm{~g}$ /day; $\mathrm{n}=2809$ ) (Burger et al., 2014). Abbreviations: $\mathrm{FB}_{\mathrm{T}}$, total fumonisins $\left(\mathrm{FB}_{1}+\mathrm{FB}_{2}+\mathrm{FB}_{3}\right)$; bw, body weight; $\mathrm{PDI}$, probable daily intake. ${ }^{\varphi} \mathrm{FB}_{\mathrm{T}}$, mean values of two independent milling experiments.

maize) suspended in a small volume of water ( $\pm 4 \mathrm{ml} / 100 \mathrm{~g}$ maize) was used when compared to the 20 and $200 \mathrm{U}$ FumD/100 g maize in a total volume of $200 \mathrm{ml}$ in the recent $\mathrm{FB}$ reduction method in maize kernels (Alberts, Schatzmayr, et al., 2019). A FB 1 hydrolysis rate of 1-5 $\mathrm{nmol} / \mathrm{min} / \mathrm{mg}$ protein for "low" and "high" FB contaminated maize utilising $20 \mathrm{U}$ FumD/100 g maize were reported after $4 \mathrm{~h}$. In the current study, lower $\mathrm{FB}_{1}$ hydrolysis rates of 0.4 and $0.2 \mathrm{nmol} / \mathrm{min} / \mathrm{mg}$ protein were recorded at FumD activities of 16 and $32 \mathrm{U}$ FumD/100 g maize, respectively. When considering the "low" FB contaminated maize, which was more aligned with the FB contamination level of the current study, an approximate 4.7-fold difference existed in the hydrolysis rate. As substrate availability will determine the conversion rate, it would appear that $\mathrm{FB}_{1}$ was more readily available presumably related to pericarp softening resulting in an increased leaching from the deeper layers of the kernel in the presence of excessive water. The low moisture content, restricted between 14.5 and $16.5 \%$ during dry milling, seems to limit leaching of FB from the inner layers which became apparent in the Super and Special maize meal products in which $\mathrm{FB}_{1}$ reduction was negligible. Therefore, efficient hydrolysis of FumD is mainly related to FB availability, specifically at the kernel surface/aqueous interphase as the enzyme seems to lack penetration into the kernel inner layer during the water restrictive conditioning stage.

The FB hydrolysis rate seems to be related to different parameters regarding the enzyme concentration and physiological conditions of the maize kernels that prevail. In the current method where whole maize kernels are utilised, the rate of FB hydrolysis is determined by substrate availability (Alberts, Schatzmayr, et al., 2019). Depending on the fungal damage, FB could colonise different layers of the kernel (Brera et al., 2004; Duncan \& Howard, 2010) and therefore, the FB level associated with each milling product will depend on the extent of fungal damage of the surface and inner layers (Bordini et al., 2017; Burger et al., 2013). In the current dry milling experimental model, complete $\mathrm{FB}_{1}$ hydrolysis was only achieved at $32 \mathrm{U} / 100 \mathrm{~g}$ maize reaching a 1:1 conversion into $\mathrm{HFB}_{1}$. The delayed $\mathrm{HFB}_{1}$ formation rates implied interesting $\mathrm{FB}_{1}$ to $\mathrm{HFB}_{1}$ conversion kinetics during dry milling. Studies in vervet monkeys and pigs reported on the incomplete hydrolyses of $\mathrm{FB}_{1}$ into the $\mathrm{HFB}_{1}$ with the presence of partial hydrolysed forms in the faeces and tissues. In vervet monkeys it was suggested that partial hydrolysis resulted in an equilibrium mixture due to intra-molecular re-arrangement of the 1,2 diol system with the $\mathrm{C}_{14}$-ester dominating (Shephard et al.,1994, 1995). This intra-molecular re-arrangement was required prior to the removal of the tricarballylic moiety from the $\mathrm{C}_{14}$ position, therefore implying a two-step enzymatic reaction for complete $\mathrm{FB}_{1}$ hydrolysis. In weaned piglets the partially hydrolysed form was also the main metabolite in the faeces and tissues investigated (Fodor et al., 2008). These studies support the apparent delay in $\mathrm{FB}_{1}$ hydrolysis during dry milling as portrayed in the current study with an excess FumD required for complete conversion of FB yielding a hydrolysis ratio reaching 1:1.

The efficacy of FumD during the dry milling conditioning stage of maize seems to be related to FB located in the outer pericarp layer of the maize kernel. This became evident as the most prominent reduction of FB was observed in total hominy feed whilst the Super and Special maize meal products showed very little reduction. An increased FB reduction efficacy was noticed when considering the Semolina milling product since it is known to contain more pericarp (Burger et al., 2013). The decreased hydrolysis rate as a function of increased FumD enzyme activity is related to excess enzyme activities resulting in substrate depletion. Therefore, the selection of an optimal enzyme concentration is complicated by not only the availability of FB at the kernel surface/aqueous interphase, but also as a function of the diffusion rate of FB from the inner layers. The level of contamination, which will determine the FB concentration in the pericarp versus that in the inner layers, are key determinants in the selection of the optimal enzyme concentration during dry milling. As the enzyme mainly seems to interact on the kernel surface and tends not to enter into the kernel, the diffusion rate of the inner layers during the $4 \mathrm{~h} 10$ min conditioning period was insufficient to affect the FB levels in the Super and Special maize meal products. However, it should be realised that for the accurate determination of the hydrolysis rates, partially hydrolysed forms are likely to exist, which were not determined in the current study. In addition, it is also not known whether FB hydrolysis occurred during milling of the degermed maize, which will depend on the activity and level of FumD in each of the milling products.

From a risk assessment perspective, reduction methods to eradicate mycotoxins in food have therefore become important as technological advances provided opportunities to safeguard human populations to their adverse biological effects. Although strict regulations by introducing maximum levels (MLs) for mycotoxins to control mycotoxin levels prevail, they are less strictly enforced or sometimes even lacking in low income countries. The MLs for $\mathrm{FB}_{1}$ and $\mathrm{FB}_{2}$ combined in maize have been set by the Codex Alimentarius Commission at $2 \mathrm{mg} / \mathrm{kg}$ maize meal and $4 \mathrm{mg} / \mathrm{kg}$ raw maize (FAO, 2014). A recent study indicated that these MLs are not practical in a South African and/or African context as maize is a major dietary staple (Shephard et al., 2019). Adult 
consumption levels and children feeding practices proved them risk populations to the adverse effects of FB (Burger et al., 2014). Community and technological based mycotoxin reduction methods have been suggested and their application under different scenarios, underlying the risk to different populations, critically evaluated (Alberts et al., 2016, 2017). Introduction of FumD targeting FB decontamination during dry milling could therefore be an alternative approach to reduce exposure to the fumonisins.

Although most of FB was eliminated during the degerming stage and forms part of the total hominy feed product which is mainly intended for oil refinery and animal feed (Brera et al., 2004), the other milling products enter into the human food chain and pose a risk to certain populations utilising maize meal as main dietary staple (Burger et al., 2014). From a risk perspective, the introduction of FumD during dry milling is only relevant when utilising Semolina and total hominy feed as a dietary food source while no effect was noticed in the Special maize meal while Super maize meal was not affected although it did not pose a risk even in the absence of FumD. When considering regional FB exposure in human populations in South Africa, a mycotoxins risk assessment model (MYCORAM) predicted that consumption of maize containing $100 \mu \mathrm{g} \mathrm{FB} / \mathrm{kg}$, approximately $4 \%$ of a population are exposed above the PMTDI limit of $2 \mu \mathrm{g} \mathrm{FB/kg} \mathrm{bw/day} \mathrm{(Burger} \mathrm{et} \mathrm{al.,} \mathrm{2014).} \mathrm{Recently,} \mathrm{a}$ similar ML level for FB in maize was suggested to safeguard children, while in adults a level of $300 \mu \mathrm{gB} / \mathrm{kg}$ was proposed (Shephard et al., 2019). The $\mathrm{FB}_{\mathrm{T}}$ levels in the milling products exceeded these levels as the PDIs of children and adults exceeded the PMTDI with FumD impacting on reconstructed whole maize, Semolina and total hominy feed. When considering the PDI's in children, FumD reduced exposure when considering reconstructed whole maize and Semolina. In adults, the PDI's of reconstructed whole maize, Semolina and total hominy feed products reached levels below the PMTDI. Therefore, commercial dry milling utilising FumD detoxification could greatly contribute to reducing the risk of exposure of humans and animals to the carcinogenic FBs. Possible application in rural subsistent communities utilising rudimentary maize milling practices, and the reduction of FB in the total reconstructed maize also provide unique opportunities to reduce PDI's far below the regulatory PMTDI of $2 \mu \mathrm{g} / \mathrm{kg}$ bw/day.

When considering the total hominy feed milling product, incorporation of FumD during the dry milling process could be beneficial, not only for the animal feed and biofuel production industries, but have important implications for human nutrition. Hominy feed is considered one of the most valuable feed ingredients and contains a wide range of phytochemicals, minerals, crude proteins, crude fat, crude fibers lignin and starch as well as insoluble ash and fatty acids (Ai \& Jane, 2016; KBAF, 2020). In the animal industry the use of hominy feed when mixed with other feed ingredients, produces best results in the quality of meat and eggs in birds, increased milk production in dairy cattle, as well the quality of fish meat. The co-products of bioethanol production from maize, i.e. wet and dry distillers' grains and solubles (WDG and DDGS), are increasingly being marketed as protein-rich and cost-saving inclusion in livestock and poultry feed (Pereira et al., 2014). As low grade maize is generally used for bioethanol production, high concentrations of fumonisins ( $>4 \mathrm{mg} / \mathrm{kg}$ ) are detected in WDG and DDGS following the fermentation and distillation processes. Incorporation of these products into pig feed has been estimated to result in economic losses of millions of dollars in the USA (Wu \& Munkvold, 2008). FumD significantly reduces the level of $\mathrm{FB}_{\mathrm{T}}$ in the hominy feed product thereby provide support for the increasing demand for WDG and DDGS, incorporated into animal feed.

With respect to health food products, the bran component of total hominy feed is considered a popular health food and the eradication of fumonisins is likely to have significant economic implications (Ai \& Jane, 2016; Pereira et al., 2014). Future enrichment of maize meal products with these bran constituents could provide products with higher dietary fibre and other bioactive constituents compared to the more refined products such as the Special and Super maize meal, thereby enhancing its health beneficial properties. Studies indicated that the regular consumption of whole grain maize lowers the risk of developing chronic diseases such as cancer, cardiovascular disease, type 2 diabetes and obesity, and improves digestive health (Sheng et al., 2018). This further emphasises the benefits of utilising FumD during dry milling of maize containing high levels of FB.

To summarise, the reduction of $\mathrm{FB}_{\mathrm{T}}$ levels in total hominy feed following dry milling of maize in the presence of FumD could open up new applications, i.e. (i) extended use in the animal feed industry providing a far safer product and (ii) incorporation as a source of maize bran in maize-based foods intended for human consumption. The adaption of enzymatic detoxification of FB could provide an alternative approach to reduce exposure in animals and humans. Cost effectiveness of upscaling such a FumD FB dry milling method to an industrial level requiring up to $40000 \mathrm{U}$ FumD/ton maize, will depend on the safety benefits of consuming the milling products as well as the commercial value of the total hominy feed lacking $\mathrm{FB}_{\mathrm{T}}$.

\section{Funding}

This research was funded by the South African Maize Trust, Project MTM 16/05.

\section{CRediT authorship contribution statement}

Johanna F. Alberts: Conceptualization, Funding acquisition, Project administration, Methodology, Investigation, Supervision, Validation, Formal analysis, Data curation, Writing - original draft, Writing review \& editing. Ibtisaam Davids: Formal analysis, Investigation, Data curation. Wulf-Dieter Moll: Resources, Methodology, Writing - review \& editing. Gerd Schatzmayr: Resources, Methodology, Writing - review \& editing. Hester-Mari Burger: Investigation, Data curation, Writing review \& editing. Gordon S. Shephard: Methodology, Data curation, Writing - review \& editing. Wentzel C.A. Gelderblom: Conceptualization, Methodology, Data curation, Writing - review \& editing.

\section{Declaration of competing interest}

The authors declare no conflicts of interest.

\section{Acknowledgements}

The authors thank the reputable and prominent South African maizebased manufacturing company and their staff for valuable assistance. Dr JP Rheeder for assistance with the preparation of the experimental maize sample.

\section{References}

Ai, Y., \& Jane, J.-L. (2016). Macro nutrients in corn and human nutrition. Comprehensive Reviews in Food Science and Food Safety, 15, 581-598.

Alberts, J., Rheeder, J., Gelderblom, W., Shephard, G., \& Burger, H.-M. (2019a). Rural subsistence maize farming in South Africa: Risk assessment and intervention models for reduction of exposure to mycotoxins. Toxins, 11, 334. https://doi.org/10.3390/ toxins11060334

Alberts, J. F., Lilly, M., Rheeder, J. P., Burger, H. M., Shephard, G. S., \& Gelderblom, W. C. A. (2017). Technological and community-based methods to reduce mycotoxin exposure. Food Control, 73, 101-109.

Alberts, J. F., Schatzmayr, G., Moll, W.-D., Davids, I., Rheeder, J. P., Burger, H.-M., .. Gelderblom, W. C. A. (2019b). Detoxification of the fumonisin mycotoxins in maize: An enzymatic approach. Toxins, 11, 523. https://doi.org/10.3390/toxins11090523

Alberts, J. F., van Zyl, W. H., \& Gelderblom, W. C. A. (2016). Biologically based methods for control of fumonisin-producing Fusarium species and reduction of the fumonisins. Frontiers in Microbiology, 7, 548. https://doi.org/10.3389/fmicb.2016.00548

Bordini, J. G., Ono, M. A., Garcia, G. T., Fazani, V. H. M., Vizoni, E., Rodrigues, K. C. B., Hirooka, E. Y., \& Ono, E. Y. S. (2017). Impact of industrial dry-milling on fumonisin redistribution in non-transgenic corn in Brazil. Food Chemistry, 220, 438-443.

Brera, C., Debegnach, F., Grossi, S., \& Miraglia, M. (2004). Effect of industrial processing on the distribution of fumonisin $B_{1}$ in dry milling corn fractions. Journal of Food Protection, 67, 1261-1266. 
Burger, H.-M., Lombard, M. J., Shephard, G. S., Danster-Christians, N., \& Gelderblom, W. C. A. (2014). Development and evaluation of a sensitive mycotoxin risk assessment model (MYCORAM). Toxicological Sciences, 141, 387-397.

Burger, H.-M., Lombard, M. J., Shephard, G. S., Rheeder, J. P., \& Van der Westhuizen, L. (2010). Dietary fumonisin exposure in a rural population of South Africa. Food and Chemical Toxicology, 48, 2103-2108.

Burger, H.-M., Shephard, G. S., Louw, W., Rheeder, J. P., \& Gelderblom, W. C. A. (2013). The mycotoxin distribution in maize milling fractions under experimental conditions. International Journal of Food Microbiology, 165, 57-64.

Cawood, M. E., Gelderblom, W. C. A., Vleggaar, R., Behrend, Y., Thiel, P., \& Marasas, W. F. O. (1991). Isolation of the fumonisins: A quantitative approach. Journal of Agricultural and Food Chemistry, 39, 1958-1962.

Duncan, K. E., \& Howard, R. J. (2010). Biology of maize kernel infection by Fusarium verticillioides. Molecular Plant-Microbe Interactions, 23, 6-16.

Eckhoff, S. R. (2004). Maize/Dry milling. In C. Wrigley, C. Walker, \& H. Corke (Eds.), Encyclopedia of grain science (pp. 216-225). Oxford, United Kingdom: Elsevier publishers, ISBN 9780080926636.

FAO, Food and Agriculture Organisation of the United Nations. (2014). Maximum levels of fumonisin in maize and maize products, Codex Alimentarius Commission, Geneva. Available online: http://www.fao.org/news/story/en/item/238558/icode/. (Accessed 20 February 2020).

Fodor, J., Balogh, K., Weber, M., Miklós, M., Kametler, L., Pósa, R., Mamet, R., Bauer, J., Horn, P., Kovács, F., \& Kovács, M. (2008). Absorption, distribution and elimination of fumonisin $\mathrm{B}_{1}$ metabolites in weaned piglets. Food Additives \& Contaminants, 25 , 88-96.

Gelderblom, W. C. A., Cawood, M. E., Snyman, S. D., Vleggaar, R., \& Marasas, W. F. O. (1993). Structure-activity relationships of fumonisins in short-term carcinogenesis and cytotoxicity assays. Food Chemistry and Toxicology, 31, 407-414.

Grenier, B., Bracarense, A. F. L., Schwartz, H. E., Lucioli, J., Cossalter, A., Moll, W.-D., Schatzmayr, G., \& Oswald, I. P. (2013). Biotransformation approaches to alleviate the effects induced by Fusarium mycotoxins in swine. Agricultural and Food Chemistry, 61, 6711-6719.

Grenier, B., Schwartz-Zimmermann, H. E., Gruber-Dorninger, C., Dohnal, I., Aleschko, M., Schatzmayr, G., Moll, W.-D., \& Applegate, T. J. (2017). Enzymatic hydrolysis of fumonisins in the gastrointestinal tract of broiler chickens. Poultry Science, 96, 4342-4351.

Heinl, S., Hartinger, D., Thamhesl, M., Kunz-Vekiru, E., Krska, R., Schatzmayr, G., Moll, W., \& Grabherr, R. (2010). Degradation of fumonisin $B_{1}$ by the consecutive action of two bacterial enzymes. Journal of Biotechnology, 145, 120-129.

KBAF, Kitale Best Animal Feeds. (2020). Benefits and uses of maize bran. Available online: https://kitalebestanimalfeeds.com/2018/09/07/benefits-and-uses-of-maizebran/. (Accessed 9 May 2020).

Lombard, M. J., Steyn, N., Burger, H.-M., Charlton, K., Senekal, M., \& Gelderblom, W. C. A. (2014). A proposed method to determine fumonisin exposure from maize consumption in a rural South African population using a culturally appropriate food frequency questionnaire. Public Health Nutrition, 17, 131-138.

Masching, S., Naehrer, K., Schwartz-Zimmermann, H.-E., Sãrãndan, M., Schaumberger, S., Dohnal, I., Nagl, V., \& Schatzmayr, D. (2016). Gastrointestinal degradation of fumonisin $\mathrm{B}_{1}$ by carboxylesterase FumD prevents fumonisin induced alteration of sphingolipid metabolism in Turkey and swine. Toxins, 8, 84. https:// doi.org/10.3390/toxins8030084

NCSS 2019. (2019). Statistical software. Kaysville, Utah, USA: NCSS, LLC. Available online: ncss.com/software/ncss. (Accessed 30 May 2020).

Pereira, M. L., Malfeito-Ferreira, M., Macri, A., Belc, N., \& Sousa, I. (2014). Hominy feed value for bioethanol and bakery functional Ingredient. International Journal of Food Processing Technology, 1, 1-9.

Rosenstrater, K. A., \& Evers, A. D. (2018). Dry milling technology. In K. Rosenstrater, \& A. Evers (Eds.), Kent's technology of cereals. An introduction for students of food science and agriculture (pp. 421-514). Cambridge, United Kingdom: Woodhead Publishing, ISBN 9780081005293.

Sharma, V., Moreau, R. A., \& Singh, V. (2008). Increasing the value of hominy feed as a coproduct by fermentation. Applied Biochemistry and Biotechnology, 149, 145-153.

Sheng, S., Li, T., \& Liu, R. (2018). Corn phytochemicals and their health benefits. Food Science and Human Wellness, 7, 185-195.

Shephard, G. S., Burger, H.-M., Rheeder, J. P., Alberts, J. F., \& Gelderblom, W. C. A. (2019). The effectiveness of regulatory maximum levels for fumonisin mycotoxins in commercial and subsistence maize crops in South Africa. Food Control, 97, 77-80.

Shephard, G. S., Thiel, P. G., Sydenham, E. W., \& Savard, M. E. (1995). Fate of a single dose of ${ }^{14} \mathrm{C}$-labelled fumonisin $\mathrm{B}_{1}$ in vervet monkeys. Natural Toxins, 3, 145-150.

Shephard, G. S., Thiel, P. G., Sydenham, E. W., Vleggaar, R., \& Alberts, J. F. (1994). Determination of the mycotoxin fumonisin $\mathrm{B}_{1}$, and identification of its partially hydrolysed metabolites in the faeces of non-human primates. Food and Chemical Toxicology, 32, 23-29.

Shisana, O., Labadarios, D., Rehle, T., Simbayi, L., Zuma, K., Dhansay, A., Reddy, P., Parker, W., Hoosain, E., Naidoo, P., Hongoro, C., Mchiza, Z., Steyn, N. P., Dwane, N., Makoae, M., Maluleke, T., Ramlagan, S., Zungu, N., Evans, M. G., Jacobs, L., Faber, M., \& SANHANES-1 Team. (2014). The South African national health and nutrition Examination survey, 2012: SANHANES-1: The health and nutritional status of the nation. Cape Town, South Africa: HSRC Press.

Steyn, N. P., Nel, J. H., \& Casey, A. (2003). Secondary data analysis of dietary surveys undertaken in South Africa in order to determine usual food consumption of the population. Public Health Nutrition, 6, 631-644.

Tshalibe, R. S., Rheeder, J. R., Alberts, J. F., Taljaard-Krugell, C., Gelderblom, W. C. A., Shephard, G. S., Lombard, M. J., \& Burger, H.-M. (2020). Multi-mycotoxin exposure of children ( 0 - 24 months) in rural maize-subsistence farming areas of the Eastern Cape Province, South Africa. World Mycotoxin Journal. https://doi.org/10.3920/ WMJ2019.2439, 1875-0796 online.

Vanara, F., Scarpino, V., \& Blandino, M. (2018). Fumonisin distribution in maize drymilling products and by-products: Impact of two industrial degermination systems. Toxins, 10, 357. https://doi.org/10.3390/toxins10090357

WHO, World Health Organization. (2001). Fumonisin $\mathrm{B}_{1}$, safety evaluation of certain mycotoxins in food. WHO Food Additives Series, 47, 103-279. http://www.inchem. org/documents/jecfa/jecmono/v47je01.htm. (Accessed 22 May 2020).

Wu, F., \& Munkvold, G. P. (2008). Mycotoxins in ethanol co-products: Modelling economic impacts on the livestock industry and management strategies. Journal of Agricultural and Food Chemistry, 56, 3900-3911. 